\title{
Brian Paltridge, Sue Starfield (eds.), The Handbook of English for Specific Purposes
}

Boston: Wiley-Blackwell, 2013

\section{Shaeda Isani}

\section{QpenEdition \\ Journals}

\section{Electronic version}

URL: http://journals.openedition.org/asp/3806

DOI: $10.4000 /$ asp.3806

ISSN: 2108-6354

\section{Publisher}

Groupe d'étude et de recherche en anglais de spécialité

\section{Printed version}

Date of publication: 1 November 2013

Number of pages: 192-198

ISSN: 1246-8185

Electronic reference

Shaeda Isani, «Brian Paltridge, Sue Starfield (eds.), The Handbook of English for Specific Purposes », ASp [Online], 64 | 2013, Online since 01 November 2013, connection on 02 November 2020. URL : http://journals.openedition.org/asp/3806 ; DOI : https://doi.org/10.4000/asp.3806

This text was automatically generated on 2 November 2020 .

Tous droits réservés 


\section{Brian Paltridge, Sue Starfield (eds.), The Handbook of English for Specific}

\section{Purposes}

Boston: Wiley-Blackwell, 2013

\section{Shaeda Isani}

\section{REFERENCES}

Paltridge, Brian and Sue Starfield (eds.). 2013. The Handbook of English for Specific Purposes. Boston: Wiley-Blackwell. 592 pp. ISBN: 978-0-470-65532-0.

\section{EDITOR'S NOTE}

The title of the book review in the paper publication was "Quo vadis? Past, present and future aspects of ESP". 
1 In spite of its relatively young age, English for Specific Purposes is today quite literally the most global of language disciplines and exists, in some form or the other, in practically every country in the world. ${ }^{1}$ Research in the field is fecund, dynamic and diversified as befits a discipline that is intrinsically international, intercultural and interdisciplinary. Like Munby's 1978 Communicative Syllabus Design, Hutchinson and Waters' 1987 English for Specific Purposes: A Learning-Centred Approach, Swales' 1990 Genre Analysis: English in Academic and Research Settings, and DudleyEvans and St John's 1998 Developments in English for Specific Purposes: A Multidisciplinary Approach, for example, The Handbook of English for Specific Purposes (2013) - "a state of the art survey of research in ESP" (p. 2) according to its editors, Brian Paltridge and Sue Starfield - is undeniably set to become a landmark publication in ESP studies.

ESP studies are defined in a straightforward and pragmatic way as

[referring] to the teaching and learning of English as a second or foreign language where the goal of the learners is to use English in a particular domain. [...] A key feature of an ESP course is that the content and aims of the course are oriented to the specific needs of the learners. ESP courses, then, focus on the language, skills, and genres appropriate to the specific activities the learners need to carry out in English. (p. 2)

3 Although the definition may appear narrow-angled and restrictive to researchers who view ESP in its broader perspective of specialized language, discourse and culture (Petit 2002: 2) $)^{2}$ or who, like Bhatia (2004) have moved away from pedagogic applications towards the analysis of specialized varieties of English as objects of study per se, the defining framework proposed by the editors has the merit of providing a mainstream working definition with regard to the otherwise complex issue of defining the scope and aim of ESP studies.

\section{Editorial characteristics}

Composed of twenty-eight essays, the volume is divided into six parts bookended by an opening article on the history of ESP by Ann M. Johns and a closing one on its future by Diane Belcher, former and current editors of the discipline's flagship journal, English for Specific Purposes. The main body of essays is divided into four parts, each related to what may be considered as one of the major macro-domains of ESP studies:

- Part I. "ESP and Language Skills" comprising five chapters dealing with the four traditional language skills; ${ }^{3}$ 
- Part II. "Areas of ESP Research" comprising ten chapters which cover both traditional and more recent ESP subject-domains;

- Part III. "ESP and Pedagogy" comprising three chapters respectively on three core ESP interests, i.e., needs analysis and curriculum development, genre and ESP, and assessment in ESP, and a fourth chapter on a more recent domain, that of the role of technology in ESP pedagogy;

- Part IV. "Research Perspectives and Methodologies in ESP Research" comprising seven chapters devoted to established and, more largely, to emerging areas of ESP research.

Given the quality of the contributions, the term Handbook in the title, connotative as it is of manuals and instruction guides, may be suggestive of an introductory nuts-andbolts guide for the novice ESP teacher. This is far from so as The Handbook is about ESP research and one of its strengths is that it holds something of interest for everyone involved in this field of enquiry, ranging from experienced ESP researchers to doctoral students, as the editors indicate:

The audience for the Handbook is students, teachers, and researchers with an interest in English for specific purposes research, as well as people working in the areas of language studies, language teaching, and applied linguistics more generally. [...] The book is also a reference work for scholars with an interest in researching this particular area of language teaching and learning. (p. 1)

In view of its multi-audience purpose, care has been taken to make the volume as userfriendly as possible, as illustrated by the attention paid to defining terms, concepts and theories referred to, cross-referencing, providing background contextualisation, avoiding over-technical jargon, etc., all of which prove invaluable even for the experienced researcher with regard to the newer specialisms presented in the volume. Contributions are methodically presented as self-contained chapters and may be read as stand-alone articles, the inevitable (but minor) defect of this quality being a certain degree of redundancy for the reader who undertakes the nevertheless stimulating experience of reading the volume as a whole.

\section{International: endogenous or exogenous learning contexts?}

7 Thirty-one authors were commissioned to contribute to the different chapters of The Handbook of whom a number - Diane Belcher, John and Lynne Flowerdew, Dan Douglas, Ken Hyland, Ann M. Johns, Catherine Nickerson, and Brian Paltridge, for example, are widely-known figures in the ESP world. In this context, the absence of two such eminently authoritative ESP figures as John Swales and Vijay K. Bhatia from the roster of authors commissioned to contribute to this collection on current ESP studies appears somewhat conspicuous, a paradox underlined by the bibliometric evidence of their work present throughout the volume, a palimpsest testimony to the extent and influence of their contribution to ESP studies the world over.

8 The contributions to the volume are written by an international bevy of ESP specialists representing major loci of ESP studies, Australia, Canada, Hong Kong, the United Kingdom, the United States and Singapore. However, in view of the very global dimension of the discipline, the term "international" needs to be nuanced. With regard to the language learning context in general, it is important to bear in mind a fundamental variable introduced by how close the learning context is situated to 
Kachru's inner circles, i.e., whether the learning takes places in a linguistically endogenous (English-speaking) or exogenous (non-English-speaking) environment. ESP learning in an endogenous English-speaking environment runs parallel to the multiple EGP (and ESP) acquisition opportunities available beyond the prescribed confines of the classroom, whereas ESP learning in an exogenous non-English-speaking context most of Europe and Latin America, and large parts of Asia and Africa, for example remains a comparatively simulated and/or ICT-mediated experience.

Keeping this variable in mind, and in spite of the editors' affirmation that "ESP research is clearly not the property of the English-speaking world, nor is it taking place solely in English-speaking countries" (p. 133), the fact remains that the majority of contributions to The Handbook are written by researchers working in the essentially linguistically endogenous environments of "host" countries (Australia, Canada, Hong Kong, Singapore, the UK, the USA and New Zealand), whereas a small minority represent exogenous ESP learning environments (France, Japan, China and the UAE). This underlying but essential variance necessitates a gentle caveat lector with regard to some of the research presented and the subsequent need to relativize when evaluating its relevance to linguistically exogenous learning situations.

\section{Subject-domains: towards multiperspective interdisciplinarity}

10 Part II of the volume, "Areas of ESP Research", is the most substantial of the four parts, comprising ten contributions, each one devoted to a specific subject-domain. No single volume can be expected to cover the entire spectrum of ESP-related subject-domains and the editors have made a discerning selection between foundational and mature areas as EST and aviation English, more mainstream ones such as EAP (in linguistically endogenous contexts), ELP, EMP, EBP, and, finally, such relatively emerging ones as workplace English, thesis and dissertation writing, and ERPP (English for research publication purposes).

11 The number and nature of subject-domains which possess their own specific language and culture makes ESP studies a necessarily eclectic and composite area of research. It also entails the risk of the "time-poor academics and teachers" (Krishnamurthy and Kosem, cited in Nesi, p. 408) that we ESP researchers-cum-practitioners are, tending to over-focus on their particular specialism at the inevitable risk not only of losing sight of "the big ESP picture" but also of being left behind with regard to the evolution of the discipline. As recent ESP research increasingly emphasizes, the need to "de-blinker" is no longer an option given the groundswell movement away from monolithic specialisms towards the demand for multiperspective expertise characterized by disciplinary hybridisation and over-laps, genre cross-overs and colonization, genre sets, interdiscursivity, etc. As Hyland underlines in the case of learners (and therefore necessarily relevant to teachers as well), “... business students may be expected to confront texts from accountancy, economics, financial management, corporate organisation, marketing, statistics, and so on" (p. 105). A volume such as The Handbook is an effective and stimulating means of "de-blinkering" specialism-specialists, offering them, in addition to a more holistic and systemic view of their discipline, multiple entry points into subject-domains at the nexus of their own specialism. 


\section{Research: updates and new perspectives}

12 One of the richest aspects of The Handbook is undoubtedly its presentation of current ESP research. In a subject-domain perspective, it provides new insights into such foundational ESP areas as science and technology, law, medicine, and business studies, and in a cross-disciplinary perspective, it serves the dual purpose of updating research in the more documented areas of enquiry as corpus studies, English as a lingua franca, intercultural rhetoric ("[...] the study of written discourse between and among individuals with different cultural backgrounds" p. 427), and presenting more recent perspectives, such as the multisemiotic (visual, written, oral, proxemic and gestural) nature of multimodality in oral presentations, the ethnographic approach (as method, methodology and deep theorizing) to situated needs analysis, gender and race related to ESP, and, last but not least, the more radical and iconoclastic area of "critical perspectives" which challenges the very foundations and defining precepts of the discipline. Amongst the diversity of subjects presented, three lines of enquiry emerge as points of interest common to many of the contributors, English as a lingua franca, critical perspectives and the status of English as the language of research publication.

13 The "de-anglicization" or "indigenization" of English and its phenomenal escalation as a global lingua franca is analyzed by Catherine Nickerson, a pioneer in ELF studies, in her contribution "English for Specific Purposes and English as a Lingua Franca" and is also a recurrent theme in other contributions. The research presented raises troubling questions with regard to one of the most fundamental precepts of teaching English in most European (and other) universities, i.e., the fact that native-speaker referenced norms are now an obsolete reference since "native speaker competence is not a primary goal" (Feak, p.36), and is even considered counter-productive (Nickerson, p. 451). In the light of this evolution, several contributions (Hyland p. 105; Parkinson p. 163; Marra p. 186; Bargiela-Chiappini and Zhang p.195; Thompson p. 283; John Flowerdew p.316; Lynne Flowerdew p. 337) highlight the "mismatch" or "disjoint" observed between pedagogy and research, between English as it is now used for professional purposes the world over and English as it is institutionally taught. Given that ESP is essentially a teaching-related discipline, the implications of such findings are far-reaching and challenge some canonical precepts regarding the norms which define acceptability and transgression: what, it may be asked, is the point of teaching our business studies learners, for example, to handle grammatical structures they will never be called on to use or hear and content to which they will never have to relate to? As Nickerson states, “... global English requires a re-evaluation of learner's needs including the most appropriate teachers to teach it, the most appropriate textbooks to use, and the most appropriate accents to use as models." (p. 450) - not to forget, the most appropriate criteria to assess language competence defined in terms of transactional and relational skills rather than linguistic ones.

14 "Critical perspectives" is a radical rethinking of ESP objectives and finalities, an approach with which one may or may not agree but which, nonetheless, raises questions which provide stimulating food for thought. It is one of the dominant ideas to emerge in current research, as highlighted by The Handbook and evidenced by the fact that it is a recurrent reference throughout the volume. "Critical Perspectives on ESP" by Sue Starfield outlines the tensions between the traditional pragmatic ESP approach which aims to equip learners with the language skills necessary to function 
professionally, and the militant and ideological critical perspectives approach, which views such "vulgar pragmatism" (Pennycook 1997, cited in Starfield p. 465) as unquestioning acceptance and Bourdienne reproduction of the norms and power asymmetry established by the dominant majority and its power holders (teachers, employers, institutions and funding bodies). The approach challenges ESP's cornerstone premise of needs analysis as correlated to present or future disciplinary/ professional insertion, calling instead for an approach based on "rights analysis" aiming at individual betterment, empowerment and social insertion.

Critical perspectives focuses largely on ESP teaching in the context of EAP and immigrant resettlement and work courses, two ESP learner profiles more largely prevalent in such linguistically endogenous host countries as Australia, the United States and Canada, for example, but less so in the many linguistically exogenous learning environments where the objective of ESP teaching is to help students, whether indigenous or international, to integrate their present or future professional communities at international level, an objective students themselves identify with. Developing learners' awareness of their rights is unquestionably commendable, but may be akin to putting the cart before the horse in that teaching learners the language skills which enable them to integrate professionally is perhaps a first step towards social integration and empowerment - as Hyland suggests, helping learners negotiate expected communicative practices also equips them with the tools needed to critique those practices (2004 as cited in Belcher p. 536), or again, Bargiela-Chiappini and Zhang who point out that "[a]daptation of ideas and models usually comes after adoption [...]" (p. 205).

16 The hegemonic status of English as the mandatory language of publishing research the Tyrannosaurus rex of the academic world, as Swales puts it (1997, cited in Starfield, p. 474) - is another key issue raised in The Handbook. Several contributors underline the fact that, though LSP is a global discipline and that research in one language is often interrelated to other languages, the field is dominated by ESP research which in turn is subject to two interdependent criteria, publishing in English and in "central" journals, (as opposed to "periphery" journals to borrow John Flowerdew's metaphor, p. 304).

17 Ironically, The Handbook is in itself a reflection of this trend: if we are proud to see a GERAS member amongst the contributors commissioned, and to find the work of several other GERAS members cited throughout the book, it is somewhat disheartening to realise that the references derive almost exclusively from "central" journals and not from contributions by the same authors to ASp, a journal of some repute published by GERAS.

18 Research in ESP/LSP is prolific but a good part of it is "inaccessible" because, as Ann M. Johns remarks in her opening chapter on the history of ESP, “... there has always been considerable localized, on-site ESP/LSP research that is either unpublished, published in a language other than English, or in local journals." This, as John Flowerdew points out, citing Gibbs, results in "lost science" (p. 301) for the ESP research community as a whole in that research not published in mainstream English-speaking journals is overlooked, leading to the duplication of already existing research. Examples abound of parallel research which never meets. One example of such "lost science" is today's emphasis on the "situated" and "ethnographic" approach in ESP pedagogy, an ESP approach initiated in the 1980s (p. 468) and paralleled by French and Swiss researchers 
a decade or so earlier who summed it up by the very apt observation, "l'apprenant est aussi une personne". ${ }^{4}$ In the same vein, the increasing pressure to move away from the narrow-angle approach which characterized early ESP towards a more holistic ethnographic one as represented in Jean Parkinson's graphic (p.156) of concentric circles illustrating "the expanding focus of ESP" reminiscent of Geert Hofstede's famous "cultural onion", or in Ulla Connor and William Rozycki's analysis of the multiple layers of professional cultural identity, meshes with the French vision which holds that l'anglais de spécialité is inseparable from the professional and/or specialized sociocultural environment from which it stems. On a different plane, Alan Hirvela's proposal to introduce "a Literature for specific purposes framework" (p. 89) segues with one of France's most innovative contributions to ESP research, i.e., the identification and codification of popular contemporary specialized fictional narrative as a genre christened fiction à substrat professionnel (FASP) and its relevance to ESP teaching (Petit 1999; Isani 2004).

ESP researchers across borders have much to share and exchange. Regrettably, short of introducing mandatory publishing in English and through open access media, there seem to be no immediately foreseeable solutions to making ESP research globally accessible. Until then, The Handbook of English for Specific Purposes fills the vacuum. More than a handbook, it is a companion to all researchers in ESP studies.

\section{BIBLIOGRAPHY}

Bhatia, Vijay K. 2004. Worlds of Written Discourse: A Genre-Based View. London: Continuum.

Dudley-Evans, Tony and Maggie-Jo St John. 1998. Developments in English for Specific Purposes. A Multi-Disciplinary Approach. Cambridge: Cambridge University Press.

Hutchinson, Tom and Alan Waters. 1987. English for Specific Purposes. Cambridge: Cambridge University Press.

Kachru, Braj B. 1985. "Standards, codification and sociolinguistic realism: The English language in the outer circle". In Quirk, R. and H. Widdowson (eds.), English in the World: Teaching and Learning the Language and Literatures. Cambridge: Cambridge University Press, 11-30.

Hofstede, Geert. 1984. Culture's Consequences: Comparing values, behaviors, institutions and organizations across nations. Thousand Oaks, CA: Sage.

Isani, Shaeda. 2004. "FASP and the genres within the genres". In Petit, M. \& S. Isani (eds.), Aspects de la fiction à substrat professionnel. Bordeaux: Université de Bordeaux, 25-36.

Munby, John. 1978. Communicative Syllabus Design. Cambridge: Cambridge University Press.

Swales, John. 1990. Genre Analysis, English in Academic and Research Settings. Cambridge: Cambridge University Press.

Petit, Michel. 1999. "La fiction à substrat professionnel : une autre voie d'accès à l'anglais de spécialité.” ASp 23-26, 57-81. 
Petit, Michel. 2002. "Éditorial”. ASp 35-36, 57-81.

\section{NOTES}

1. ESP can also lay claim to the merit of being the nucleus from which interest in the area spread to other language disciplines, giving rise to Français à objectifs spécifiques, Español para fines especificos, Deutsch als Fachsprache, Italiano per scopi speciali, etc., thus legitimating the creation of the umbrella discipline of Languages for Specific Purposes (LSP).

2. "L'anglais de spécialité est la branche de l'anglistique qui traite de la langue, du discours et de la culture des communautés professionnelles et groupes sociaux spécialisés anglophones et de l'enseignement de cet objet."

3. The fifth chapter does not correspond to the notion of five skills as interpreted by a growing number of researchers today, i.e., reading, writing, listening, speaking and oral interaction, but to "Vocabulary and ESP".

4. Translation: "A learner is also a person."

\section{AUTHORS}

\section{SHAEDA ISANI}

Université Stendhal, Grenoble 